\title{
ADVANCED TECHNOLOGIES FOR STRIPPER GAS WELL ENHANCEMENT
}

\section{QUARTERLY REPORT}

October 1, 2004 - December 31, 2004

Ronald J. MacDonald, P.G.

Senior Petroleum Geologist

Principal Investigator

April 27, 2005

DE-FG26-99FT40700

Schlumberger

Data \& Consulting Services

1310 Commerce Drive

Park Ridge 1

Pittsburgh, PA 15275-1011 


\section{DISCLAIMER}

This report was prepared as an account of work sponsored by an agency of the United States Government. Neither the United States Government nor any agency thereof, nor any of their employees, makes any warranty, express or implied, or assumes any legal liability or responsibility for the accuracy, completeness, or usefulness of any information, apparatus, product, or process disclosed, or represents that its use would not infringe privately owned rights. Reference herein to any specific commercial product, process, or service by trade name, trademark, manufacturer, or otherwise does not necessarily constitute or imply its endorsement, recommendation, or favoring by the United States Government or any agency thereof. The views and opinions of authors expressed herein do not necessarily state or reflect those of the Unites States Government or any agency thereof. 


\section{ABSTRACT}

As part of Task 1 in Advanced Technologies for Stripper Gas Well Enhancement, Schlumberger Data \& Consulting Services (DCS) joined with two Appalachian Basin producers, Great Lakes Energy Partners, LLC, and Belden \& Blake Corporation to develop methodologies for identification and enhancement of stripper wells with economic upside potential. These industry partners previously provided us with data for more than 700 wells in northwestern Pennsylvania.

Phase 1 goals of this project were to develop and validate methodologies that can quickly and cost-effectively identify underperforming wells with remediation potential. We enhanced and streamlined our software and are using it with Microsoft's ${ }^{\text {TM }}$ Access and Excel programs. During the last quarter of 2002, Great Lakes provided us with additional data for approximately 2,200 wells located in their Cooperstown field situated in northwestern Pennsylvania. We identified approximately 220 potential remediation candidates and Great Lakes' personnel reviewed this list for viability and selected more than twenty five wells to be reworked. Approximately fifteen wells have been successfully reworked as of year-end 2004. This field provided a rigorous test of our software and analytical methods.

We processed all the information provided to us including the Cooperstown data. Great Lakes also provided supplemental data listing the original operator of the wells. 


\section{TABLE OF CONTENTS}

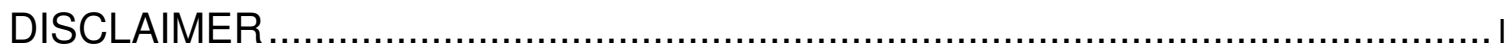

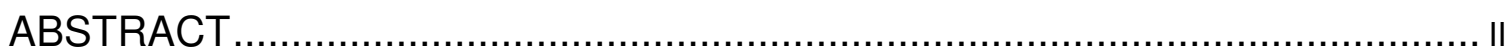

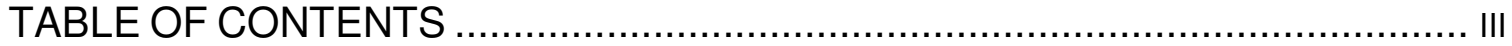

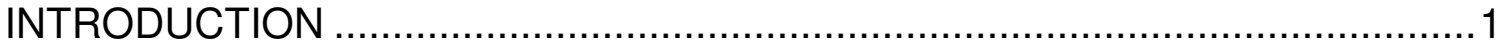

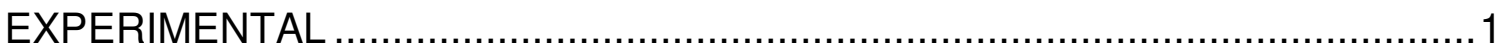

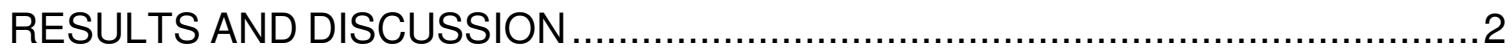

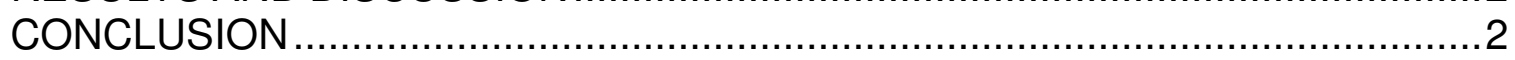




\section{INTRODUCTION}

During this report period we worked with our industry partner, Great Lakes Energy Partners, LLC (Great Lakes). In prior months, we worked with data obtained from a second industry partner, Belden \& Blake Corporation $(\mathrm{B} \& \mathrm{~B})$. As mentioned in our last update, Great Lakes supplied data for approximately 205 wells located in Warren, Venango, and Crawford counties, Pennsylvania, and B\&B provided information for \pm 501 wells situated in Venango and Warren counties, Pennsylvania. We used this data to test and improve our Microsoft ${ }^{\mathrm{TM}}$ Access/Excel software, and distinguish underperformers.

As an enhancement to our analysis, Great Lakes provided us with production data for 2,200 additional wells for the Cooperstown Field, which is located in Crawford, Venango, and Indiana Counties, Pennsylvania. Final evaluation of this field has been finished, more than 220 candidates have been chosen, and approximately fifteen have been reworked based on our study.

\section{EXPERIMENTAL}

We utilized our software tools to conduct a rapid, first-pass search for wells possessing enhancement/remediation potential. To begin the process, we generated a single Production Indicator (PI) capable of representing the entire production life of a well. The software has the ability to calculate two PI's (x-year cumulative versus Date of First Production (DOFP), and normalized rate versus DOFP). The first indicator is obtained by determining the cumulative gas production over a user-specified input period (e.g. 3 $\mathrm{yr}, 5 \mathrm{yr}, 8 \mathrm{yr}$, etc.) versus a well's DOFP, and the second PI is determined by calculating the normalized (i.e. the average monthly production rate for the desired year) gas production rate for the chosen year of production.

We then compared the PI's of a target well relative to the average of its offsets within a chosen radius (e.g. 5,000 ft), and identified target wells that are underperforming.

The software compares the PI of a target well to the average indicator of its offsets. A user chooses a percentage (e.g. $>=50 \%$ ) that a target well's PI must be below the wells within its domain in order to be recognized as a low-performer. The entire well list is processed and all qualifying target wells that meet the chosen criteria are listed. This provides a rapid, efficient, and automated method to identify wells that are underperformers and that may have potential for production enhancement.

Our first pass of the original data is finished and we identified a list of wells with promising enhancement potential. We discussed these results with B\&B and Great Lakes and reviewed the completion, geologic, and production data in detail. We further refined our list with the Cooperstown data and established a good basis for a Phase II field demonstration. 


\section{RESULTS AND DISCUSSION}

DOE has successfully beta-tested the SWARM software. A user-friendly interface has been designed as this is of major importance in making the program relatively easy and inexpensive to use by the operators. Enhanced features such as generating applicable location maps and rate-time plots have been added.

\section{CONCLUSION}

We received data for almost 3,000 wells from which wells with possible production enhancement potential were recognized. The software has been tested and it successfully provides an easy and rapid way to identify wells that may have rework potential.

A Final Technical Report is being written.

We have used the new software and our experience in the Appalachian Basin to generate a list of candidates with enhancement upside. The software is working properly and we have confirmed that the methodologies developed can quickly and economically identify stripper wells with upside potential. By accomplishing this, we have assisted producers throughout the U.S. to increase their existing gas production and increase the U.S. natural gas reserve base. 